\title{
INTERCOM FOR A FIRE BRIGADE TRUCK
}

\author{
POSPISILIK, M[artin] \& ADAMEK, M[ilan]
}

\begin{abstract}
In this paper a design and construction of a simple duplex intercom for a fire brigade truck is introduced. The device has been built and tested. It allows the officer in charge, sitting on the front seat, to communicate with the crew located at the back side of the truck. Moreover, the intercom is accommodated in that way there was a possibility to reproduce the output of the radio receiving set or wireless transmitter, being situated in the cabin of the officer in charge, in the crew cabin
\end{abstract}

Key words:fire brigade truck, intercom, duplex communication, amplifier

\section{INTRODUCTION}

The motivation to create the intercom module emerged from a need of such device in a small volunteer firefighters' crew. The main requirements were as follows:

- easy application in the truck,

- cheap and easy production of small series without a need of special devices,

- possibility of duplex communication,

- electrical and mechanical endurance.

These requirements were fulfilled with the design described in this paper. The block diagram of the intercom implementation is depicted in Fig. 1.

As can be seen in the figure, there are two loudspeakers installed in the crew cabin and one in the officer in charge cabin. In both cabins switchable microphones are installed as well. It is advisable the highest possible distance between the loudspeakers and the microphones was achieved. The communication is fully duplex so both sides can talk simultaneously.

The intercom board incorporates two amplifiers with symmetrical inputs. Moreover, there is a set of two additional symmetrical inputs so radio receiver or transmitter output can be reproduced in the crew cabin as well.

The aim was to achieve as simple construction as possible. The whole intercom is integrated on one printed circuit board and all the devices are flat enough so it can be installed inside a thin box.

Moreover, in order higher loudness of the voice was achieved, the amplifiers are equipped with a non-linear feedback that enables to reach higher output power without increasing the supply voltage that is usually limited by the voltage in the supply network of the truck.
Implementation of the feedback is described in the further text of this paper.

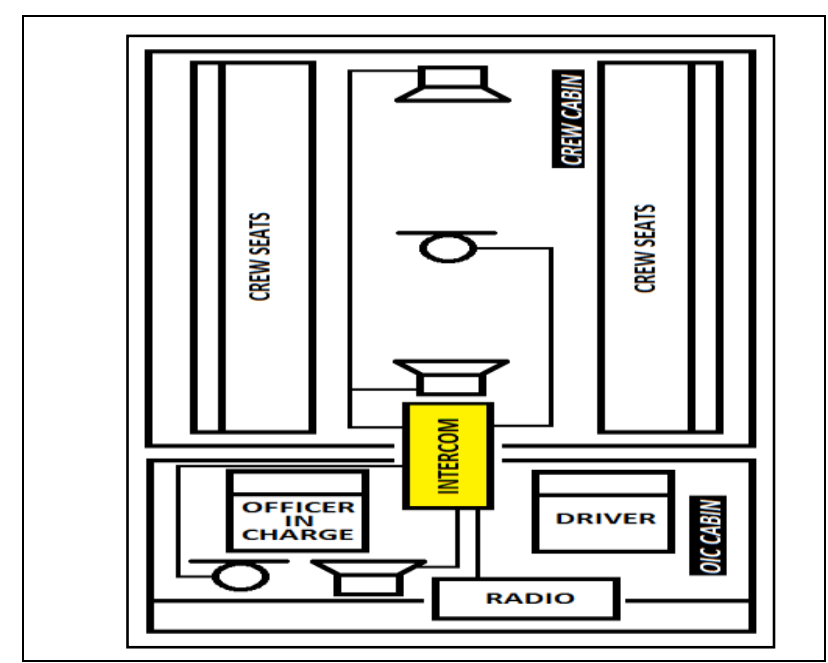

Fig. 1. Block diagram of the intercom system installed in a fire truck

\section{CIRCUITRY DESIGN}

The whole intercom is realized on one printed circuit board. The circuitry schematics can be seen in Fig. 2. It consists of two power amplifiers IC2 and IC3 TDA1905. These amplifiers are driven by differential amplifiers based on quad low-voltage operational amplifier IC4 TLC274 [5]. The channel from the crew to the officer in charge uses only one symmetrical microphone input. The contraflow channel uses three symmetrical inputs, one for the microphone and two for connecting additional radio device. It is supposed the connected device is not accommodated for connection of the intercom. This is why the appropriate inputs are also symmetrical with DC decoupling. This enables to connect the intercom to the loudspeakers powered by the radio device.

The whole circuit is supplied with the on-board voltage, typically $14.4 \mathrm{~V}$. Pads 1 and 2 serves for connecting the supply voltage. To prevent the circuit from damage caused by short-time overvoltage, a transil D2 is implemented behind the fuse F1. The power amplifiers are fed directly from the decoupling capacitor C2 while the differential amplifiers are fed by the regulated voltage that should be approximately $11 \mathrm{~V}$. The IC1 is a 78L09 stabiliser and it is supposed to suppress the potential interferences that can get into the circuit from the electrical system of the vehicle. The D3 diode shall be green with the threshold voltage of $2.1 \mathrm{~V}$. It emits light when the intercom is on and increases the output voltage of the voltage stabilizer. 
All the differential inputs are tied to a bias of approximately $5.25 \mathrm{~V}$ which is the best bias for the operating amplifiers in this configuration, verified by simulations. With this bias their symmetrical voltage swing is as high as possible. The input impedance of all the inputs is decreased by resistors R14, R25, R33 and R41 which decreases the possibility of inducing interferences to the connection leads. Moreover, the inputs are equipped with DC decoupling capacitors that, in case of microphone inputs, serves also as lowfrequency filters, protecting the amplifiers from overexcitation with mechanical noise in the truck. The overall gain of both channels can be adjusted by R20 and R37 rotary trimming resistors to prevent the intercom of creating a positive feedback among the microphones and the loudspeakers. The sum of both channel gains shall be slightly lesser than 1 in the whole frequency range so no positive feedback could occur. The gain of the microphone inputs is approximately $28 \mathrm{~dB} @ 1 \mathrm{kHz}$ while the gain of line-in inputs is $-12 \mathrm{~dB} @ 1 \mathrm{kHz}$.

When the intercom is turned on, the power amplifiers are muted for the couple of seconds until the capacitor C5 charges up to at least $1.9 \mathrm{~V}$. This enables the "silent turn-on". The power amplifiers chips are designed to be used in automotive industry and are connected according to the manufacturer's hints, but there is a non-linear element created by two anti-paralell LEDs added in their feedback loop. These LEDs are to create small distortion that results in the signal curve compression before the power amplifiers are overexcitated.By this, the total harmonic distortion is increased but
IC2 and IC3 chips are in flat DIL16 package, being cooled by the PCB copper clad via pins 9 to 16 . This solution has ben applied in accordance with [4]. More information on using non-linear feedbacks can be found in [2], [1], [3].

\section{MEASUREMENTS}

The intercom was built and underwent a series of physical measurements. Let us mention the most interesting results.

\subsection{Output power}

The output power of the amplifiers was measured with and without the influence of the non-linear feedback. The circuit was driven by the sinusoidal signal at the frequency of $1 \mathrm{kHz}$, the outputs were loaded with the load of $4 \Omega$ and the RMS voltage at the load was measured by a digital oscilloscope. The results are depicted in Fig. 3. It is obvious that with the linear feedback the output power is limited to $5 \mathrm{~W}$ due to peak clipping while when the non-linear feedback was applied, the output power reached up to $6 \mathrm{~W}$. This quasicompression brought the following advantages:

- higher mean value of the signal energy resulting in higher subjective perception of the signal loudness,

- less sharp-clippings but higher total harmonic distortion at higher loudness but this is not critical,

- lower power dissipation at the amplifier when driven to the highest power.

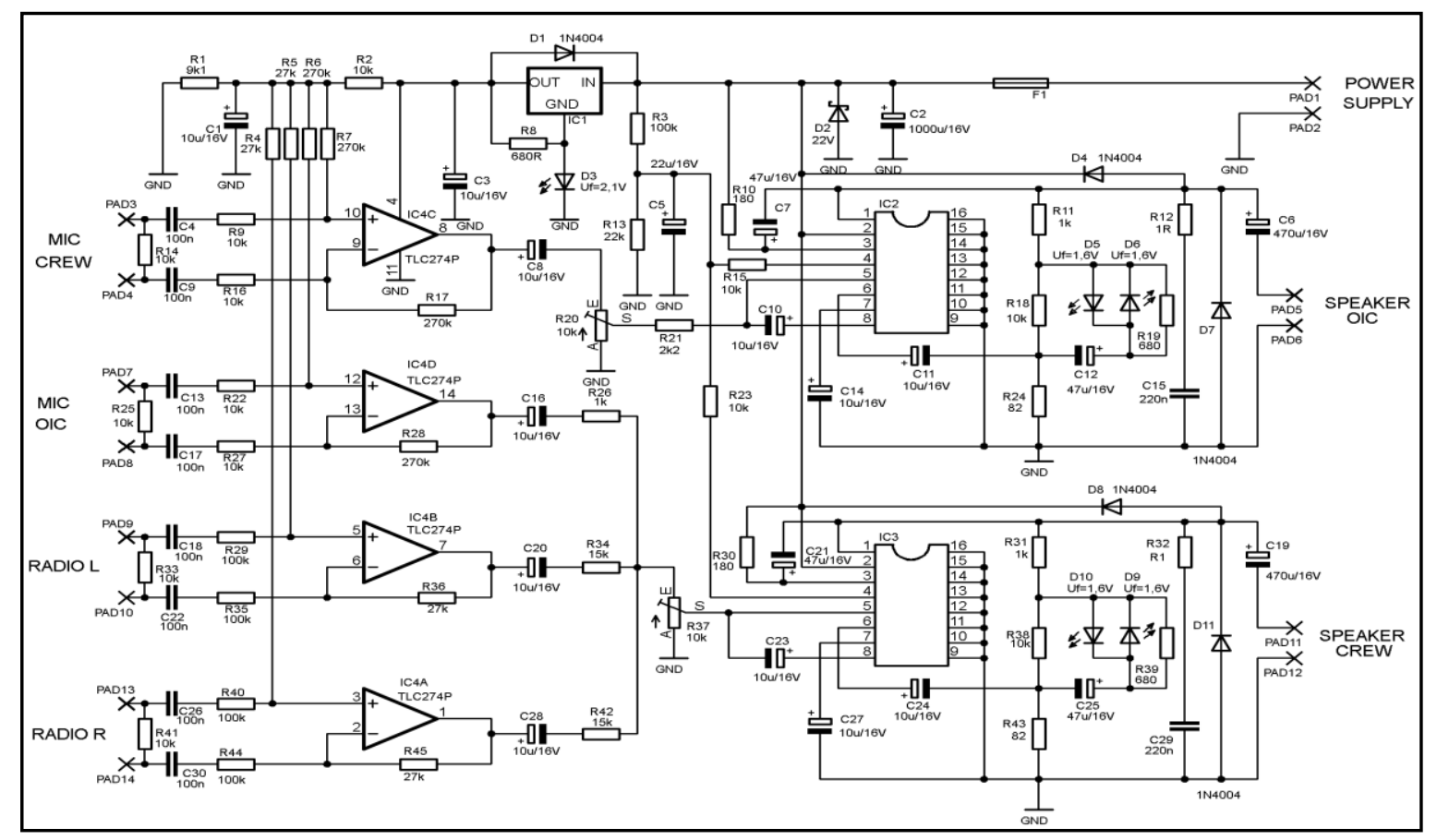

Fig. 2. Intercom circuitry schematics

the efficient output power is increased as well by $20 \%$ from 5 to $6 \mathrm{~W}$ without the need of increasing the supply voltage and improving the chip cooling. For this reason this solution can be considered to be satisfactory. The
The Total harmonic distortion is kept below $20 \%$ at the maximum output power of $6 \mathrm{~W}$. Although this number seems high, due to soft-clipping introduced by the nonlinear feedback the ratio of harmonics is different from the one produced when the amplifier is limiting 
hard and the comprehensibility of the transmitted message is not affected.

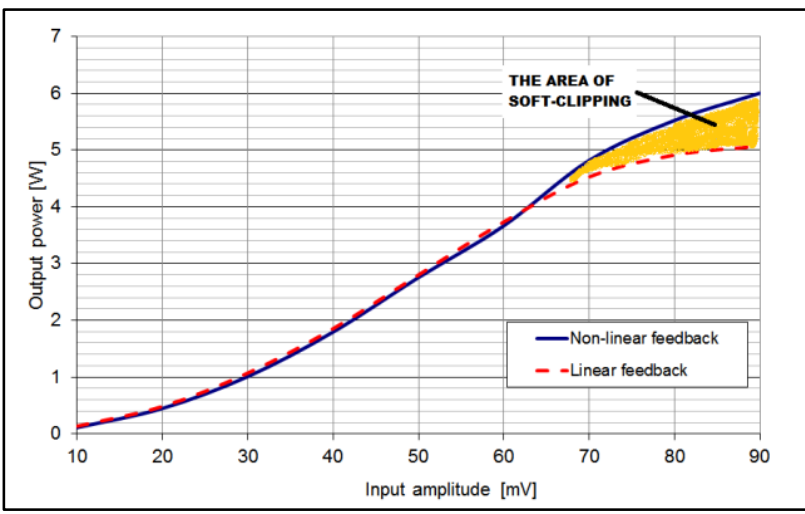

Fig. 3. The measured effect of the non-linear feedback

\subsection{Frequency response}

The tolerance bandwidths for both, the microphone and the radio symmetrical inputs, are depicted in the figure below. The measurements confirmed that all the inputs fulfilled the prescribed bandwidth specifications.

Obviously, the measurement of the frequency response was processed at the output power of approximately $1 \mathrm{~W}$ in order the effect of the non-linear feedback did not affect the results.

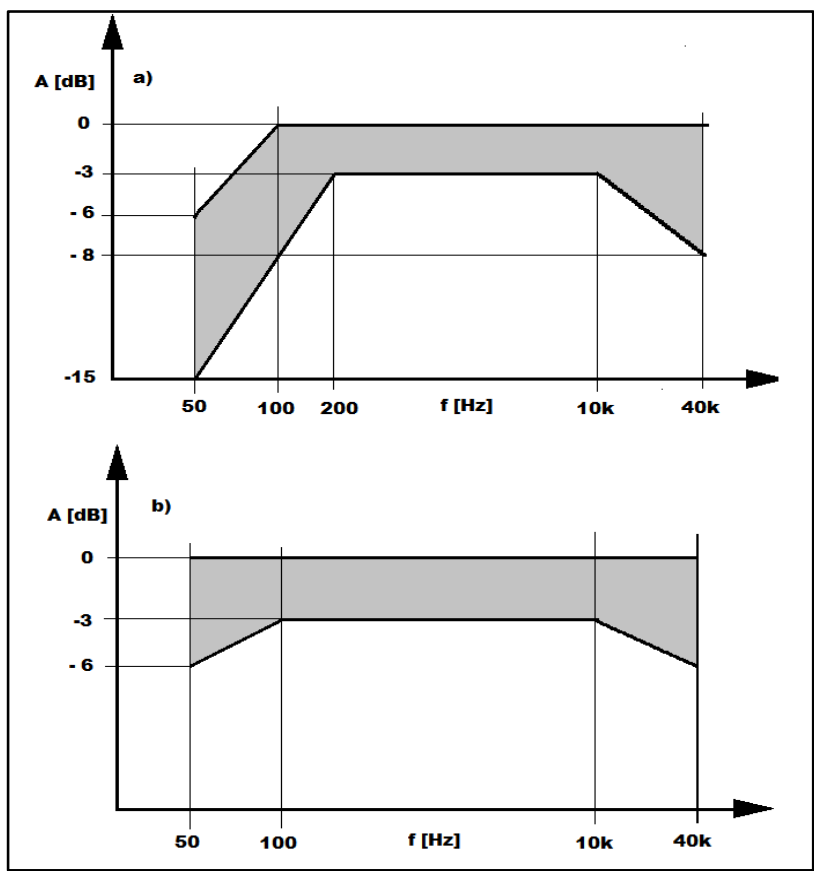

Fig. 4. Frequency response tolerances for microphone inputs (a) and symmetrical line inputs (b)

\subsection{Power consumption and efficiency}

The power consumption and efficiency was measured at the supply voltage of $14 \mathrm{~V}$ at different levels of the amplifier excitation. The results are enlisted in the following table.

\begin{tabular}{|c|c|c|c|}
\hline $\begin{array}{c}\text { Output } \\
\text { power } \\
{[\mathbf{W}]}\end{array}$ & $\begin{array}{c}\text { Current } \\
\text { consumption } \\
{[\mathbf{m A}]}\end{array}$ & $\begin{array}{c}\text { Power } \\
\text { consumption } \\
{[\mathbf{W}]}\end{array}$ & $\begin{array}{c}\text { Efficiency } \\
{[\%]}\end{array}$ \\
\hline 0 & 130 & 1.8 & - \\
\hline $2 \times 4.5$ & 1,100 & 15.4 & 58.4 \\
\hline $2 \times 6$ & 1,400 & 19.6 & 61.2 \\
\hline
\end{tabular}

Tab. 1. Power consumption versus output power

\subsection{Sensitivity}

The sensitivity was measured as an input voltage needed to achieve the output power of $5.5 \mathrm{~W}$. The measurement was obtained with the signals the frequency of which was $1 \mathrm{kHz}$. The results are enlisted in the table below.

\begin{tabular}{|l|l|}
\hline Inputs & Sensitivity \\
\hline Microphones & $15 \mathrm{mV}$ each \\
\hline Symmetrical line & $2 \times 4.5 \mathrm{~V}$ \\
\hline
\end{tabular}

Tab. 2. Input sensitivities

\subsection{Signal to noise ratio}

The signal to noise ratio was measured directly, which means that no weighting filter was applied. The noise level was measured as RMS signal value measured by a digital oscilloscope when all the inputs of the circuit were shorted to the ground. As the reference signal level, the voltage at the output of the amplifier reached at the output power of $1 \mathrm{~W}$ and the frequency of $1 \mathrm{kHz}$ was considered. The achieved signal to noise ratio was $50 \mathrm{~dB}$.

\section{MECHANICAL CONSTRUCTION}

The whole circuitry is built on one printed circuit board that is mounted in a thin plastic box. The capacitors of higher capacity must be of axial type, being placed horizontally. The displacement of the devices is depicted in Fig. 5.

The printed circuit board was designed in order the prototype version could easily be produced without special technologies. Only one layer is employed, using the poured copper as a ground, shielding and power amplifiers cooling. The integrated circuits of the power amplifiers can be seen in the upper part of the picture, which refers to the back side of the device. One side of each chip pins is soldered to the poured copper acting as a heatsink, as recommended by the chip producer [4]. However, in order to increase the reliability of the device, it is recommended to to provide the integrated power circuits with small taped heatsings.

The connectors are of Jack $6.3 \mathrm{~mm}$ (microphones and loudspeakers) and $3.5 \mathrm{~mm}$ (line inputs) types. They are mounted on the front and rear panel of the plastic box, being connected by wires to the appropriate pads displaced on the printed circuit boards. The input and output pads are not placed in one line in order the design of the printed circuit board was simpler, and wire jumpers could be avoided.

The fuseholder is mounted in the way it was accessible through the appropriate hole in the rear panel of the plastic box.

In order the construction was cheap and easy, conventional devices were used and normalized dimensions were preferred. Moreover, the values of the devices were unified as much as possible in order the devices could be purchased in greater amounts, resulting in lower total price. Moreover, using the unified devices simplifies the printed circuit board assembling. The bill of material documenting this effort is enlisted in Table 3. 


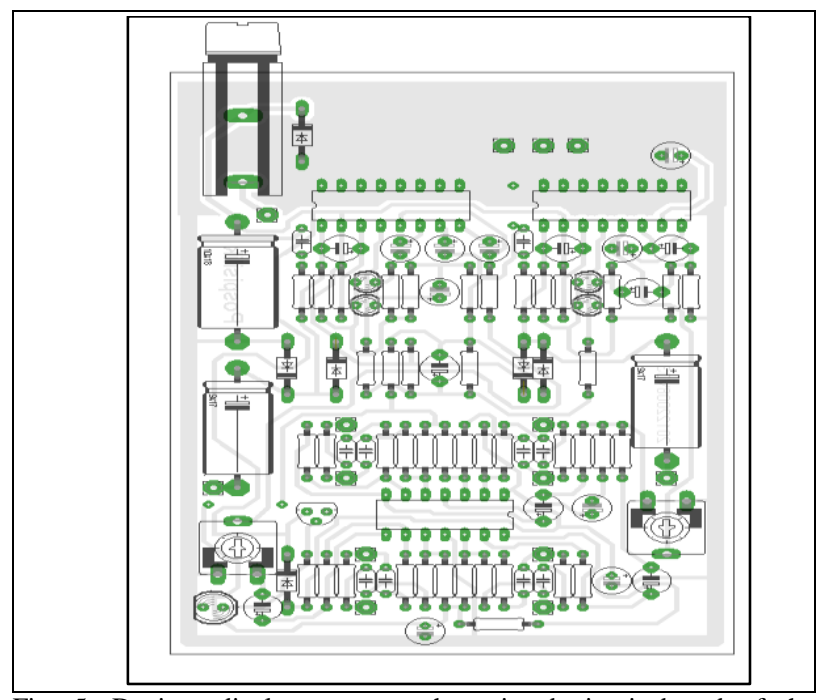

Fig. 5. Devices displacement on the printed circuit board of the intercom

\begin{tabular}{|c|c|c|c|}
\hline Position & Value/Type & $\begin{array}{l}\text { Total } \\
\text { pes }\end{array}$ & Comment \\
\hline \multicolumn{4}{|l|}{ Resistors } \\
\hline $\mathrm{R} 1$ & $9.1 \mathrm{k} \Omega$ & 1 & $0207 / 10$ \\
\hline $\begin{array}{l}\text { R2, R9, R14, R15, } \\
\text { R16, R18, R22, } \\
\text { R23, R24, R27, } \\
\text { R33, R38, R41 }\end{array}$ & $10 \mathrm{k} \Omega$ & 13 & 0207/10 \\
\hline $\begin{array}{l}\text { R3, R29, R35, } \\
\text { R40, R44 }\end{array}$ & $100 \mathrm{k} \Omega$ & 5 & $0207 / 10$ \\
\hline R4, R5, R36, R45 & $27 \mathrm{k} \Omega$ & 4 & $0207 / 10$ \\
\hline R6, R7, R17, R28 & $270 \mathrm{k} \Omega$ & 4 & $0207 / 10$ \\
\hline R8, R19, R39 & $680 \Omega$ & 3 & $0207 / 10$ \\
\hline $\mathrm{R} 10, \mathrm{R} 30$ & $180 \Omega$ & 2 & $0207 / 10$ \\
\hline $\mathrm{R} 11, \mathrm{R} 26, \mathrm{R} 31$ & $1 \mathrm{k} \Omega$ & 3 & $0207 / 10$ \\
\hline R12, R32 & $1 \Omega$ & 2 & $0207 / 10$ \\
\hline $\mathrm{R} 13$ & $22 \mathrm{k} \Omega$ & 1 & $0207 / 10$ \\
\hline $\mathrm{R} 20, \mathrm{R} 37$ & $10 \mathrm{k} \Omega$ & 2 & $\begin{array}{l}\text { Trim. res. } \\
\text { CA9-Vertical } \\
\end{array}$ \\
\hline $\mathrm{R} 21$ & $2.2 \mathrm{k} \Omega$ & 1 & 0207/10 \\
\hline $\mathrm{R} 24, \mathrm{R} 43$ & $82 \Omega$ & 2 & $0207 / 10$ \\
\hline $\mathrm{R} 34, \mathrm{R} 42$ & $15 \mathrm{k} \Omega$ & 2 & $0207 / 10$ \\
\hline \multicolumn{4}{|l|}{ Capacitors } \\
\hline $\begin{array}{l}\mathrm{C} 1, \mathrm{C} 3, \mathrm{C} 8 \mathrm{C} 10, \\
\mathrm{C} 11, \mathrm{C} 14, \mathrm{C} 16, \\
\mathrm{C} 20, \mathrm{C} 23, \mathrm{C} 24, \\
\mathrm{C} 27, \mathrm{C} 28\end{array}$ & $10 \mu \mathrm{F} / 16 \mathrm{~V}$ & 12 & RAD $5 \mathrm{~mm}$ \\
\hline $\mathrm{C} 2$ & $1 \mathrm{mF} / 16 \mathrm{~V}$ & 1 & $\mathrm{AX} 22 \times 10$ \\
\hline $\begin{array}{l}\mathrm{C} 4, \mathrm{C} 9, \mathrm{C} 13, \mathrm{C} 17, \\
\mathrm{C} 18, \mathrm{C} 22, \mathrm{C} 26, \\
\mathrm{C} 30\end{array}$ & $100 \mathrm{nF} / 50 \mathrm{~V}$ & 8 & Ceramics \\
\hline $\mathrm{C} 5$ & $22 \mu \mathrm{F} / 16 \mathrm{~V}$ & 1 & RAD $5 \mathrm{~mm}$ \\
\hline C6, C19 & $470 \mu \mathrm{F} / 16 \mathrm{~V}$ & 2 & $\mathrm{AX} 22 \times 9$ \\
\hline $\mathrm{C} 7, \mathrm{C} 12, \mathrm{C} 21, \mathrm{C} 25$ & $47 \mu \mathrm{F} / 16 \mathrm{~V}$ & 4 & RAD $5 \mathrm{~mm}$ \\
\hline $\mathrm{C} 15, \mathrm{C} 29$ & $220 \mathrm{nF} / 50 \mathrm{~V}$ & 2 & Ceramics \\
\hline \multicolumn{4}{|c|}{ Semiconductors, active devices } \\
\hline $\begin{array}{l}\text { D1, D4, D7, D8, } \\
\text { D11 }\end{array}$ & $1 \mathrm{~N} 4004$ & 4 & \\
\hline D2 & BYV10 & 1 & $22 \mathrm{~V}$ \\
\hline D3 & $3 \mathrm{~mm}$ LED & 1 & $\begin{array}{l}\mathrm{U}_{\mathrm{f}}=2.1 \mathrm{~V} \\
(\text { green })\end{array}$ \\
\hline D5, D6, D9, D10 & $3 \mathrm{~mm}$ LED & 4 & $\begin{array}{l}\mathrm{U}_{\mathrm{f}}=1.6 \mathrm{~V} \\
(\mathrm{red})\end{array}$ \\
\hline
\end{tabular}

\begin{tabular}{|l|l|l|l|}
\hline IC1 & 78 L09 & 1 & TO92 \\
\hline IC2, IC3 & TDA1905 & 2 & {$[4]$} \\
\hline IC4 & TLC274P & 1 & \\
\hline Other & & & $\begin{array}{l}\text { Holder and } \\
\text { fuse 3A/F }\end{array}$ \\
\hline F1 & KS10H & 1 & Optional \\
\hline Heatsinks & & & \\
\hline
\end{tabular}

Tab. 3. Bill of material used to assemble the PCB

\section{CONCLUSION}

In the framework of this paper the design of a duplex intercom suitable for a fire truck was described. The circuit has been constructed and proved and the results met the initial requirements. This simple low-cost duplex intercom is suitable to be employed in all vehicles divided into more cabins, making the communication among all passengers difficult - for example taxi cars, tramways with a closed driver cabin etc.

\section{ACKNOWLEDGEMENT}

Thispaperissupported by theInternal Grant Agencyat TBU in Zlin, project No. IGA/45/FAI/10/D and by theEuropeanRegionalDevelopmentFundundertheproject CEBIA-Tech No. CZ.1.05/2.1.00/03.0089.

\section{REFERENCES}

[1] Punčocháŕ, J. (1999). Operational amplifiers in electrotechnics [Operační zesilovače v elektronice]. BEN, ISBN 80-86056-37-6, Praha

[2] Neumann, P., Uhlír J. (2001).Electronic circuits and functional blocksI [Elektronické obvody a funkčni bloky I]. Vydavatelství ČVUT, ISBN 80-01-02394-X, Praha

[3] Vobecký, J., Záhlava V. (2001). Electronics - devices and circuits, principles and examples [Elektronika - soućástky a obvody, principy a príklady], GRADA Publishing, ISBN 80-7169-884-9, Praha

[4] http://www.datasheetdir.com/TDA1905+Audio-PowerAmplifier(2011) - Datasheet and list of suppliers of TDA1905 chip. Accessed on: 2011-08-20

[5] http://www.alldatasheet.com/datasheetpdf/pdf/28864/TI/TLC274.html (2011) - TLC274 datasheet Accessed on: 2011-08-20 